\title{
3 Research Square \\ Declining risk of ischemic heart disease over time in rheumatoid arthritis: 1821 patients from 1972 to 2017.
}

Christian Lillebø Alsing ( $\nabla$ chr.alsing@gmail.com )

Haraldsplass Deaconess Hospital https://orcid.org/0000-0001-7131-1592

Tone Wikene Nystad

Haukeland University Hospital: Haukeland Universitetssjukehus

Jannicke Igland

University of Bergen: Universitetet i Bergen

Clara Gram Gjesdal

Haukeland University Hospital: Haukeland Universitetssjukehus

Helga Midtb $\varnothing$

Haukeland University Hospital Department of Heart Disease: Haukeland Universitetssjukehus

Hjarteavdelinga

Grethe S. Tell

University of Bergen: Universitetet i Bergen

Bjørg-Tilde Svanes Fevang

Haukeland University Hospital: Haukeland Universitetssjukehus

\section{Research article}

Keywords: Rheumatoid arthritis, cardiovascular disease, epidemiology, inflammation

Posted Date: August 13th, 2021

DOI: https://doi.org/10.21203/rs.3.rs-789634/v1

License: (c) (1) This work is licensed under a Creative Commons Attribution 4.0 International License.

Read Full License 


\section{Abstract}

Objectives: To evaluate trends of acute myocardial infarction (AMI) and ischemic heart disease (IHD) in rheumatoid arthritis (RA) patients compared with the general population over time.

Methods: We performed a retrospective cohort study of 1821 RA patients diagnosed from 1972 to 2013. The total population of the same county (Hordaland, Norway) and time period was used for comparison. Information on AMI and IHD events was obtained from hospital patient administrative systems or cardiovascular registries. We estimated incidence rates and standardized event ratios (SER) compared with the general population by Poisson regression.

Results: There was an average annual decline of $1.6 \%$ in age- and sex-adjusted AMI incidence rates from 1972 to 2017 (incidence rate ratio 0.984, 95\% Cl 0.971-0.998). Excess events in RA patients compared with the general population declined on average 1.3\% per year for AMI and 2.3\% for IHD from 1972 to 2014. The total RA cohort had 49\% (SER 1.49, 95\% Cl 1.30-1.69) more AMI events and 63\% (SER 1.63, $95 \% \mathrm{Cl} 1.52-1.74)$ more IHD events compared with the general population. There were no significant excess AMI and IHD events for RA patients diagnosed after 1998 compared with the general population.

Conclusion: Incidence rates and excess events of AMI and IHD in RA patients declined from 1972 to 2017. There were no excess AMI or IHD events in RA patients diagnosed after 1998 compared with the general population.

\section{Background}

Rheumatoid arthritis (RA) patients have 1.5 to 2.0 times increased risk of acute myocardial infarction (AMI) and ischemic heart disease (IHD) compared with the general population [1,2]. The AMI risk seems to increase within the first years after RA diagnosis, but is similar to that of the general population before diagnosis [3-6]. Mortality rates for RA patients are about 50\% higher than in the general population, and cardiovascular disease (CVD) is the primary cause of death in about $40 \%$ of patients [7].

RA involves systemic and non-resolving inflammation that favours the development of atherosclerosis. The AMI risk in RA increases with higher levels of inflammation and higher disease activity [8-12]. Treatment of RA with disease-modifying anti-rheumatic drugs (DMARDs) reduces inflammation and disease activity, and is associated with a lower AMI risk [13-17].

RA treatment has improved vastly over the last two decades, in particular due to the focus on early and aggressive treatment, tight control strategies, and the use of biologic DMARDs for patients with insufficient response to synthetic DMARDs. Several studies have found higher rates of remission and better long-term outcomes in patients with early introduction of DMARDs [18]. This "window of opportunity" may be a critical phase for intervention against the development of atherosclerosis in RA. Several recent studies report a decline in the overall mortality gap between RA patients and the general population in the 21 st century, which parallels the improvement in RA treatment [19-24]. However, there 
is little information about the AMI and IHD risk in RA patients diagnosed after the introduction of modern RA treatment.

Our aim was therefore to assess if the introduction of improved RA treatment was associated with lower risk of AMI and IHD. We evaluated trends of AMI and IHD incidence in RA patients diagnosed from 1972 to 2013. RA patients were compared with the entire population of the same county and time period to estimate possible excess AMI and IHD events and to adjust for secular changes in the diagnosis of IHD. The estimates of excess risk were stratified by time of RA diagnosis to address possible RA treatmentrelated changes.

\section{Methods}

\section{Study design and setting}

We performed a retrospective cohort study of 1821 RA patients compared with the total population from the same county (Hordaland, Norway) during 1972-2014 to investigate possible excess of AMI and IHD events in RA patients. We also evaluated time trends of AMI and IHD events for RA patients from 1972 to 2017.

\section{RA patient cohort}

We evaluated all outpatient contacts or hospital admissions with an RA diagnosis at the Department of Rheumatology, Haukeland University Hospital in the period 1972 through 2013. Almost all RA patients in Hordaland county are treated at this hospital. The selection process is shown in figure 1 and explained in detail in the additional file, along with a comparison between the included and excluded RA patients. We obtained consent from 2649 patients through the Norwegian Arthritis Registry $(n=1456)$ and letters of consent from patients not included in the Norwegian Arthritis Registry $(n=214)$. Exemption from consent was allowed in patients who were dead $(n=979)$ by the Regional Committee for Medical and Health Research Ethics. The included RA patients were diagnosed during 1972-2013 by the treating rheumatologist. Most RA patients are in secondary care for several years. We therefore excluded patients with fewer than 5 hospital contacts assuming them as initially misdiagnosed, miscoded or treated at a different institution.

Data on AMI and IHD events in RA patients were obtained from the Western Norway Cardiovascular Registry (WENOCARD) (1972-2006) and from the hospital's patient administrative system (2007-2017) as illustrated in figure $2[25,26]$. We only included events where Hordaland was the current county of residence. Cause of death was obtained from the Norwegian Cause of Death Registry [27]. The Norwegian personal identification number, unique to each Norwegian resident, was used to link the data sources. 


\section{Comparison cohort}

The entire population of Hordaland county, including RA patients, was used as a comparison cohort. Population counts and data on AMI and IHD events were obtained from WENOCARD (1972-2006) and the Cardiovascular Diseases in Norway project (CVDNOR) (2007-2014) as illustrated in figure $2[25,26]$. The data on the comparison cohort were only aggregated counts and therefore considered to be anonymized. We did not have data beyond 2014 for the comparison cohort. Counts of AMI and IHD events were aggregated by year, sex and 5-year age groups. A description of WENOCARD and CVDNOR can be found in the additional file.

\section{Definition of outcomes}

The outcome of our study was AMI and IHD events. Incident events were used to estimate time trends in $\mathrm{AMI}$ and IHD, while multiple events were used to evaluate time trends in excess risk compared with the general population, as well as to estimate standardized event ratios (SER).

An incident event of AMI was defined as a hospitalization with AMI (International Classification of Diseases (ICD)-8/9; 410 and ICD-10; I21, I22) as primary or secondary discharge diagnosis or death from AMI (ICD-8/9; 410-414 and ICD-10; I20-I25) without any AMI-hospitalizations prior to RA diagnosis [28]. An incident event of IHD (ICD-8/9; 410-414 and ICD-10; I20-I25) was defined as hospitalization with IHD as primary or secondary diagnosis or death with IHD as the underlying cause of death without any IHDhospitalizations prior to RA diagnosis.

When counting multiple AMI-events and IHD-events per person a new hospitalization was counted as a new event if it occurred $>28$ days after the previous hospitalization. If the new hospitalization occurred $\leq 28$ days after the previous it was defined as a part of the previous event [25].

Data on AMI and IHD events for the RA and comparison cohort were collected from different sources, but are all based on the same discharge diagnosis codes from hospitals in Western Norway. A comparison between WENOCARD and CVDNOR showed little deviation of AMI counts in the overlapping time period (1994-2006) of 0-1.06\% [29].

\section{Statistics}

We estimated a required sample size of 7769 person-years follow-up for RA and non-RA patients to detect a standardized incidence ratio of 1.5 with $95 \%$ confidence and $80 \%$ power under the assumption of an incidence rate of 50 per 10000 in non-RA patients.

The RA patients were divided into three cohorts by time period of RA diagnosis according to main RA treatment trends: 1972-1985 (pre-Methotrexate era), 1986-1998 (Methotrexate era), 1999 and onwards (biologic era). Continuous variables are presented as means with standard deviations and categorical 
variables as numbers and proportions. Trends were estimated by linear regression for continuous variables, logistic regression for binary variables and ordinal logistic regression for variables with multiple categories. Missing values were excluded from the analyses in table 1.

Time trends in AMI and IHD incidence in RA patients were explored during 1972-2017. Incidence rate ratios (IRR) and $95 \%$ confidence intervals per one year change in calendar time were estimated using Poisson regression with year included as a continuous independent variable and adjustment for age, bmi, serological and smoking status (and sex for total estimates). Person-years were calculated from 1st January the year RA was diagnosed to the first event, death or end of study period (31st December 2017). We also performed a subanalysis of time trends from 2002 to 2017, due to the introduction of troponins in the diagnosis of $\mathrm{AMI}$ at the beginning of the $21^{\text {st }}$ century. Missing values for bmi, serological and smoking status were present in less than $5 \%$ of cases and replaced by multiple imputation using the mi function in STATA with weight and sex as an additional predictors.

Standardized event ratio (SER) was estimated by Poisson regression (figure 3) from counts of the total and RA population in Hordaland, Norway at the middle of each calendar year. Expected counts from the comparison cohort were used as an offset, stratified by year, sex and 5-year age interval to obtain indirect standardization (suppl). The model was not adjusted for additional variables such as smoking since they were unavailable for the total population. We calculated separate estimates for the total RA cohort and three diagnostic time cohorts for events occurring in the entire period (1972-2014) and for three time periods (1972-1985, 1986-1998 and 1999-2014). Separate estimates were also calculated for men, women and three age groups. There were no missing values in these analyses.

Time trends in excess risk of AMI and IHD in RA patients compared with the general population were explored by Poisson regression during 1972-2014 with year as a continuous variable to estimate event ratio ratios (ERR) for average annual change in SER. Details are presented in the additional file. There were no missing values in these analyses.

We used robust standard errors to calculate $95 \%$ confidence intervals when using Poisson regression to adjust for overdispersion. A p-value below 0.05 was considered significant.

Analyses were conducted using Stata Statistical Software (Release 16. College Station, TX: StataCorp LLC) and R version 3.6.3.

\section{Results}

\section{Patient characteristics}

Age, body mass index (BMI), prevalence of diabetes and use of antihypertensives and statins at the time of RA diagnosis increased across the diagnostic cohorts (table 1). 
The total RA cohort had a follow-up time of 23808 person-years from RA diagnosis to death or 31.12.2014, while the diagnostic cohorts (1972-1985, 1986-1998 and 1999-2013) had respectively 5600,9536 and 8672 person-years of follow-up.

\section{AMI and IHD incidence rates}

In total, 240 incident AMI and 327 incident IHD events occurred in the 1821 RA patients from 1972 to 2017 during respectively 25890 and 24345 person-years of observation.

There was an average annual decline in the AMI incidence rates of $1.6 \%$ (IRR $0.986,95 \% \mathrm{Cl} 0.970-0.999$ ) adjusted for age, sex, bmi, serological and smoking status (table 2). Similarly, adjusted IHD incidence rates declined on average $3.2 \%$ per year (IRR $0.968,95 \% \mathrm{Cl} 0.958-0.978$ ). On average, there was an increase in the AMI and IHD incidence in RA patients older than 85 years (table 2), mostly in men. Furthermore, there was no decline in AMI and IHD incidence in women aged 16-64 years. Trends in AMI and IHD incidence in the 2002-2017 subgroup (supplementary table 1) were similar to those in the total period (1972-2017).

\section{Excess AMI and IHD risk}

In total, $269 \mathrm{AMI}$ and $1325 \mathrm{IHD}$ events occurred from 1972 to 2014 in the RA cohort, while $35614 \mathrm{AMI}$ and 126974 IHD events occurred in the general population. The overall SER in RA patients compared with the general population was $1.49(95 \% \mathrm{Cl} 1.30-1.69)$ for $\mathrm{AMI}$ and $1.63(95 \% \mathrm{Cl} 1.52-1.74)$ for IHD from 1972 to 2014 . There was no excess risk in patients older than 85 years. When stratifying by diagnostic cohort and year of event (figure 3), significant excess AMI and IHD risks were seen in the total estimates for the two first diagnostic cohorts, but not in the 1999-2013 cohort (AMI: SER 1.05, 95\% Cl 0.82-1.35; IHD: SER $1.02,95 \% \mathrm{Cl}, 0.89-1.16)$. There was significant excess IHD risk, but no excess AMI risk for patients in the early phase of RA diagnosed 1985-1998. Exclusion of autoantibody-negative patients did not increase the excess risk in the 1999-2013 cohort. Men and women had similar excess risk in total and in the three diagnostic cohorts.

There was an average annual decline in the excess risk of $1.3 \%$ for AMI (ERR $0.987,95 \% \mathrm{Cl} 0.972-1.002$ ) and $2.3 \%$ for IHD (ERR 0.977, 95\% $\mathrm{Cl} 0.69-0.985)$.

\section{Discussion}

In this large and long-term RA-cohort, we found no excess risk of AMI and IHD events in patients diagnosed from 1999 and onwards, while patients diagnosed before 1999 had a significant excess risk compared with the general population. Furthermore, from 1972 to 2014 there was a decline in the excess of AMI and IHD events in RA patients compared with the general population. The excess risk was similar for both genders and autoantibody positive RA patients compared with the total RA cohort. In addition, 
we found a significant overall decline in the incidence rates of AMI and IHD among RA patients from 1972 to 2017. However, patients older than 85 years experienced an increase in AMI incidence rates.

Most previous studies have included patients with long-standing RA, diagnosed before the introduction of modern RA treatment, which could explain excess AMI risk found after the year 2000 [1,2,16,30-34]. Two recent studies found an increased risk of AMI for the total RA cohort but not for subgroups of incident RA $[35,36]$. We similarly found an increased risk of AMI and IHD compared with the general population for the total RA cohort, but not for RA patients diagnosed after 1998. Both Holmqvist and Lindhardsen et al found an elevated risk of AMI in incident RA cohorts diagnosed from 1995 and 1997 to 2006 compared with the general population, but this was before the introduction of the "treat to target" strategy $[3,4]$.

Treatment with methotrexate and biologics is associated with a lower risk of cardiovascular events [1317]. The increased use of methotrexate and biologics over time is evident in our cohort as shown in a previous study, and could explain the low AMI and IHD risk seen in RA patients diagnosed after 1998 [37]. Probably, the improved drugs and treatment strategies have reduced inflammation-driven atherosclerosis sufficiently to render the IHD risk similar to the general population. However, other possible explanations could be: less use of corticosteroids and NSAIDs; increased focus on primary CVD prevention in RA patients; and less smoking, which is a known risk factor for severe RA and is associated with decreased response to anti-rheumatic drugs [13,34,38].

Our findings are in line with several studies that did not find excess cardiovascular mortality after 2004 $[19,21,23,24,39]$. The decline in mortality was attributed to improved RA treatment, but could also be due to improved treatment and primary prevention of CVD, which may have influenced RA patients to a greater extent than non-RA individuals. Mortality data tend to underestimate IHD, and hospitalization data are preferable due to a higher positive predictive value (PPV) for AMI $[40,41]$. Our study corroborates the significant decline in cardiovascular disease in RA patients in the 21 st century by using data from hospital records. Overall, there was a decline in AMI and IHD incidence rates in RA patients during the study period. This matches findings in the general population of Norway and other countries in Europe [42-45]. However, we found an increase in elderly RA patients which is likely due to non-RA-related factors since there was no excess risk in this age group. Possible explanations could be a lower threshold for hospitalization of older patients and increased detection of type $2 \mathrm{AMI}$ after the introduction of troponins. Similar findings have been reported in the general population in Denmark and the UK [46,47]. The lack of a declining trend seen in younger women with RA is in accordance with several previous studies of the general population showing an increasing trend in younger women from around 1988 until $2009[25,48-50]$.

The main strengths of our study are the long study period of an unselected RA population stratified by time of RA diagnosis and the use of the general population as a comparison cohort. Data from regionwide registries and hospital records have ensured completeness of the outcome variables. The comparison cohort made it possible to adjust estimates of excess risk for changes in definition and diagnosis of IHD over time. 
Our study has some limitations. Substantially more patients in our cohort were diagnosed with RA in the latter time period (1999-2013). This could be due to lack of effective RA treatment in the earlier time periods and hence less referrals to secondary care especially for milder forms of RA. It is therefore possible that RA patients diagnosed during the first period had a more serious illness, which could correspond to a higher risk of IHD. We used two different sources for outcomes from 2007 and onwards for the RA and comparison cohort, but both were based on hospital discharge diagnosis codes.

Furthermore, we lacked data on smoking status for the comparison cohort, thus we could not adjust the estimates for changes in smoking. Another limitation is the use of recurrent AMI and IHD in comparison to the total population, which are likely less precise outcomes than incident AMI. A study using the Danish National Patient Registry, which is comparable to the registries in our study, found a higher PPV for incident AMI (97\%) compared to recurrent myocardial infarction (88\%) and IHD (88-93\% for stable and unstable angina) from 2010-2012.

Our findings have several clinical implications. Patients diagnosed recently with RA appear to have equal risk of IHD to the general population and should therefore receive similar primary CVD prevention. However, individual considerations should be made by the treating rheumatologist, for instance in cases of severe RA or poor response to RA treatment. Our findings support treatment of RA to a target of remission to avoid RA-related IHD and associated societal costs.

\section{Conclusions}

RA patients have historically had an excess risk of IHD compared with the general population. Our study found a decline in IHD and excess risk of IHD from 1972 to 2014 and there was no such excess risk in RA patients diagnosed after 1998. Our findings support early and aggressive treatment of RA and indicate that patients with well-controlled RA may have an IHD risk similar to the general population.

\section{List Of Abbreviations}

AMI: Acute myocardial infarction; BMI: Body mass index; CVD: Cardiovascular disease; CVDNOR: Cardiovascular Diseases in Norway project; DMARDs: Disease-modifying anti-rheumatic drugs; ERR: Event rate ratio; ICD: International Classification of Diseases; IHD: Ischemic heart disease; IRR: Incidence rate ratios; PPV: Positive predictive value; RA: Rheumatoid arthritis; SER: Standardized event ratio; WENOCARD: Western Norway Cardiovascular Registry

\section{Declarations}

Ethics approval and consent to participate: The study complies with the Declaration of Helsinki approved and was approved by the Regional Committee for Medical and Health Research Ethics, Health Region West (2014/1932). Living RA participants gave consent either through registration in the Norwegian Arthritis Registry or letters of consent. Exemption from consent was allowed in RA patients who were dead by the Regional Committee for Medical and Health Research Ethics. 
Consent for publication: Not applicable

Availability of data and materials: The datasets generated and analysed during the current study are not available since the approval by the Regional Committee for Medical and Health Research Ethics does not allow for sharing of de-identified data.

Competing interests: CLA reports grants from Western Norway Regional Health Authority during the conduct of the study. BSF reports attendance of an advisory board meeting by Eli Lilly Norge A.S Customer Meeting Services where travel expenses were paid by the company.

Funding: This work was supported by the Western Norway Regional Health Authority, Marit Hansen's Memorial fund and Aslaug Andersen's Memorial fund. The funding body did not have any influence on the design of the study or collection, analysis, and interpretation of data and in writing the manuscript.

Authors' contributions: CLA participated in the planning of the study, data collection, analysis and interpretation of the data and writing of the manuscript. BTF participated in the planning of the study, interpretation of the data and writing of the manuscript. TWN participated in the planning of the study, data collection, interpretation of the data and revision of the manuscript. CGG participated in the planning of the study and revision of the manuscript. HM participated in the planning of the study and revision of the manuscript. $\mathrm{Jl}$ participated in the planning of the study, analysis and interpretation of the data and revision of the manuscript. GST participated in the planning of the study, interpretation of the data and revision of the manuscript. All authors read and approved the final manuscript.

Acknowledgements: This work was funded by the Western Norway Regional Health Authority, Marit Hansen's Memorial fund and Aslaug Andersen's Memorial fund. The authors thank Tomislav Dimoski at The Norwegian Knowledge Centre for the Health Services, Norway for his contribution in developing the software necessary for obtaining data from Norwegian hospitals, conducting the data collection and quality assurance of data in the CVDNOR project.

Disclaimer: The interpretation and reporting of the data are the sole responsibility of the authors, and no endorsement by the Norwegian Cause of Death Registry is intended, nor should be inferred.

\section{References}

1. Schieir O, Tosevski C, Glazier RH, Hogg-Johnson S, Badley EM. Incident myocardial infarction associated with major types of arthritis in the general population: a systematic review and meta-analysis. Ann Rheum Dis. 2017;76:1396-404.

2. Han C, Robinson DW, Hackett MV, Paramore LC, Fraeman KH, Bala MV. Cardiovascular Disease and Risk Factors in Patients With Rheumatoid Arthritis, Psoriatic Arthritis, and Ankylosing Spondylitis. J Rheumatol. J Rheumatol; 2006;33. 
3. Holmqvist ME, Wedrén S, Jacobsson LTH, Klareskog L, Nyberg F, Rantapää-Dahlqvist S, et al. Rapid increase in myocardial infarction risk following diagnosis of rheumatoid arthritis amongst patients diagnosed between 1995 and 2006. J Intern Med. 2010;268:578-85.

4. Lindhardsen J, Ahlehoff O, Gislason GH, Madsen OR, Olesen JB, Torp-Pedersen C, et al. The risk of myocardial infarction in rheumatoid arthritis and diabetes mellitus: a Danish nationwide cohort study. Ann Rheum Dis. 2011;70:929-34.

5. Hannawi S, Haluska B, Marwick TH, Thomas R. Atherosclerotic disease is increased in recent-onset rheumatoid arthritis: a critical role for inflammation. Arthritis Res Ther. 2007;9:R116.

6. Holmqvist ME, Wedrén S, Jacobsson LTH, Klareskog L, Nyberg F, Rantapää-Dahlqvist S, et al. No increased occurrence of ischemic heart disease prior to the onset of rheumatoid arthritis: results from two Swedish population-based rheumatoid arthritis cohorts. Arthritis Rheum. 2009;60:2861-9.

7. Sokka T, Abelson B, Pincus T. Mortality in rheumatoid arthritis: 2008 update. Clin Exp Rheumatol. 2008;26:S35-61.

8. de Thurah A, Andersen IT, Tinggaard AB, Riis AH, Therkildsen J, Bøtker HE, et al. Risk of major adverse cardiovascular events among patients with rheumatoid arthritis after initial CT-based diagnosis and treatment. RMD Open. 2020;6.

9. Innala L, Möller B, Ljung L, Magnusson S, Smedby T, Södergren A, et al. Cardiovascular events in early RA are a result of inflammatory burden and traditional risk factors: a five year prospective study. Arthritis Res Ther. 2011;13:R131.

10. Wållberg-Jonsson S, Johansson H, Ohman ML, Rantapää-Dahlqvist S. Extent of inflammation predicts cardiovascular disease and overall mortality in seropositive rheumatoid arthritis. A retrospective cohort study from disease onset. J Rheumatol. 1999;26:2562-71.

11. Myasoedova E, Chandran A, Ilhan B, Major BT, Michet CJ, Matteson EL, et al. The role of rheumatoid arthritis (RA) flare and cumulative burden of RA severity in the risk of cardiovascular disease. Ann Rheum Dis. 2016;75:560-5.

12. Rao VU, Pavlov A, Klearman M, Musselman D, Giles JT, Bathon JM, et al. An evaluation of risk factors for major adverse cardiovascular events during tocilizumab therapy. Arthritis Rheumatol. 2015;67:37280.

13. Roubille C, Richer V, Starnino T, Collette M, Alexandra M, Fleming P, et al. The effects of tumour necrosis factor inhibitors, methotrexate, non-steroidal anti-inflammatory drugs and corticosteroids on cardiovascular events in rheumatoid arthritis, psoriasis and psoriatic arthritis: a systematic review and meta-analysis. Ann Rheum Dis. 2015;74:480-9. 
14. Lee JL, Sinnathurai P, Buchbinder R, Hill C, Lassere M, March L. Biologics and cardiovascular events in inflammatory arthritis: a prospective national cohort study. Arthritis Res Ther. 2018;20:171.

15. Low ASL, Symmons DPM, Lunt M, Mercer LK, Gale CP, Watson KD, et al. Relationship between exposure to tumour necrosis factor inhibitor therapy and incidence and severity of myocardial infarction in patients with rheumatoid arthritis. Ann Rheum Dis. 2017;76:654-60.

16. Ljung L, Askling J, Rantapää-Dahlqvist S, Jacobsson L, ARTIS Study Group. The risk of acute coronary syndrome in rheumatoid arthritis in relation to tumour necrosis factor inhibitors and the risk in the general population: a national cohort study. Arthritis Res Ther. 2014;16:R127.

17. Widdifield J, Abrahamowicz M, Paterson JM, Huang A, Thorne JC, Pope JE, et al. Associations Between Methotrexate Use and the Risk of Cardiovascular Events in Patients with Elderly-onset Rheumatoid Arthritis. J Rheumatol. 2019;46:467-74.

18. Monti S, Montecucco C, Bugatti S, Caporali R. Rheumatoid arthritis treatment: the earlier the better to prevent joint damage. RMD Open. 2015;1:e000057.

19. Provan SA, Lillegraven S, Sexton J, Angel K, Austad C, Haavardsholm EA, et al. Trends in all-cause and cardiovascular mortality in patients with incident rheumatoid arthritis: a 20-year follow-up matched casecohort study. Rheumatology . 2020;59:505-12.

20. Abhishek A, Nakafero G, Kuo C-F, Mallen C, Zhang W, Grainge MJ, et al. Rheumatoid arthritis and excess mortality: down but not out. A primary care cohort study using data from Clinical Practice Research Datalink. Rheumatology . 2018;57:977-81.

21. Lacaille D, Avina-Zubieta JA, Sayre EC, Abrahamowicz M. Improvement in 5-year mortality in incident rheumatoid arthritis compared with the general population-closing the mortality gap. Ann Rheum Dis. 2017;76:1057-63.

22. van den Hoek J, Boshuizen HC, Roorda LD, Tijhuis GJ, Nurmohamed MT, van den Bos GAM, et al. Mortality in patients with rheumatoid arthritis: a 15-year prospective cohort study. Rheumatol Int. 2017;37:487-93.

23. Puolakka K, Kautiainen H, Pohjolainen T, Virta L. No increased mortality in incident cases of rheumatoid arthritis during the new millennium. Ann Rheum Dis. 2010;69:2057-8.

24. van Nies JAB, de Jong Z, van der Helm-van Mil AHM, Knevel R, Le Cessie S, Huizinga TWJ. Improved treatment strategies reduce the increased mortality risk in early RA patients. Rheumatology . 2010;49:2210-6.

25. Sulo G, Vollset SE, Nygård O, Igland J, Egeland GM, Ebbing M, et al. Trends in acute myocardial infarction event rates and risk of recurrences after an incident event in Norway 1994 to 2009 (from a Cardiovascular Disease in Norway Project). Am J Cardiol. 2014;113:1777-81. 
26. Øyen N, Nygård O, Igland J, Tell GS, Nordrehaug JE, Irgens LM, et al. [Hospital admission rates for cardiovascular diseases in Western Norway, 1992-2001]. Tidsskr Nor Laegeforen. 2008;128:17-23.

27. Pedersen AG, Ellingsen CL. Data quality in the Causes of Death Registry. Tidsskr Nor Laegeforen. 2015;135:768-70.

28. Sulo G, Igland J, Vollset SE, Nygård O, Egeland GM, Ebbing M, et al. Effect of the Lookback Period's Length Used to Identify Incident Acute Myocardial Infarction on the Observed Trends on Incidence Rates and Survival: Cardiovascular Disease in Norway Project. Circ Cardiovasc Qual Outcomes. 2015;8:376-82.

29. Igland J, Tell GS, Ebbing M, Vollset SE, Dimoski T. The CVDNOR project: Cardiovascular Disease in Norway 1994-2009. Description of data and data quality. 2013. Available from: https://cvdnor.w.uib.no/files/2013/08/CVDNOR-Data-and-Quality-Report1.pdf. Accessed 02 May 2021.

30. Curtis JR, Yang S, Singh JA, Xie F, Chen L, Yun H, et al. Is Rheumatoid Arthritis a Cardiovascular RiskEquivalent to Diabetes Mellitus? Arthritis Care Res . 2018;70:1694-9.

31. Ljung L, Rantapää-Dahlqvist S, Jacobsson LTH, Askling J. Response to biological treatment and subsequent risk of coronary events in rheumatoid arthritis. Ann Rheum Dis. 2016;75:2087-94.

32. Fernández-Gutiérrez B, Perrotti PP, Gisbert JP, Domènech E, Fernández-Nebro A, Cañete JD, et al. Cardiovascular disease in immune-mediated inflammatory diseases: A cross-sectional analysis of 6 cohorts. Medicine . 2017;96:e7308.

33. Solomon DH, Goodson NJ, Katz JN, Weinblatt ME, Avorn J, Setoguchi S, et al. Patterns of cardiovascular risk in rheumatoid arthritis. Ann Rheum Dis. 2006;65:1608-12.

34. Wolfe F, Michaud K. The risk of myocardial infarction and pharmacologic and nonpharmacologic myocardial infarction predictors in rheumatoid arthritis: a cohort and nested case-control analysis. Arthritis Rheum. 2008;58:2612-21.

35. Pujades-Rodriguez M, Duyx B, Thomas SL, Stogiannis D, Rahman A, Smeeth L, et al. Rheumatoid Arthritis and Incidence of Twelve Initial Presentations of Cardiovascular Disease: A Population RecordLinkage Cohort Study in England. PLoS One. 2016;11:e0151245.

36. Kronzer VL, Crowson CS, Sparks JA, Myasoedova E, Davis JM 3rd. Comorbidities As Risk Factors for Rheumatoid Arthritis and Their Accrual After Diagnosis. Mayo Clin Proc. 2019;94:2488-98.

37. Nystad TW, Fenstad AM, Furnes O, Fevang BT. Predictors for orthopaedic surgery in patients with rheumatoid arthritis: results from a retrospective cohort study of 1010 patients diagnosed from 1972 to 2009 and followed up until 2015. Scand J Rheumatol. Taylor \& Francis; 2018;47:282-90.

38. Chang K, Yang SM, Kim SH, Han KH, Park SJ, Shin JI. Smoking and rheumatoid arthritis. Int J Mol Sci. 2014;15:22279-95. 
39. Myasoedova E, Gabriel SE, Matteson EL, Davis JM 3rd, Therneau TM, Crowson CS. Decreased Cardiovascular Mortality in Patients with Incident Rheumatoid Arthritis (RA) in Recent Years: Dawn of a New Era in Cardiovascular Disease in RA? J Rheumatol. 2017;44:732-9.

40. Alfsen GC, Mæhlen J. The value of autopsies for determining the cause of death. Tidsskr Nor Laegeforen. 2012;132:147-51.

41. McCormick N, Lacaille D, Bhole V, Avina-Zubieta JA. Validity of myocardial infarction diagnoses in administrative databases: a systematic review. PLoS One. 2014;9:e92286.

42. Sulo G, Igland J, Vollset SE, Ebbing M, Egeland GM, Ariansen I, et al. Trends in incident acute myocardial infarction in Norway: An updated analysis to 2014 using national data from the CVDNOR project. Eur J Prev Cardiol. 2018;25:1031-1039.

43. Schmidt M, Jacobsen JB, Lash TL, Botker HE, Sorensen HT. 25 year trends in first time hospitalisation for acute myocardial infarction, subsequent short and long term mortality, and the prognostic impact of sex and comorbidity: a Danish nationwide cohort study. BMJ. 2012;e356-e356.

44. Dégano IR, Salomaa V, Veronesi G, Ferriéres J, Kirchberger I, Laks T, et al. Twenty-five-year trends in myocardial infarction attack and mortality rates, and case-fatality, in six European populations. Heart. 2015;101:1413-21.

45. Yang D, Dzayee DAM, Beiki O, de Faire U, Alfredsson L, Moradi T. Incidence and case fatality after day 28 of first time myocardial infarction in Sweden 1987-2008. Eur J Prev Cardiol. Sage Publications Sage UK: London, England; 2012;19:1304-15.

46. Alzuhairi KS, Søgaard P, Ravkilde J, Gislason G, Køber L, Torp-Pedersen C. Incidence and outcome of first myocardial infarction according to gender and age in Denmark over a 35-year period (1978-2012). Eur Heart J Qual Care Clin Outcomes. 2015;1:72-8.

47. Bhatnagar P, Wickramasinghe K, Wilkins E, Townsend N. Trends in the epidemiology of cardiovascular disease in the UK. Heart. 2016;102:1945-52.

48. Towfighi A, Zheng L, Ovbiagele B. Sex-specific trends in midlife coronary heart disease risk and prevalence. Arch Intern Med. 2009;169:1762-6.

49. Arora S, Stouffer GA, Kucharska-Newton AM, Qamar A, Vaduganathan M, Pandey A, et al. Twenty Year Trends and Sex Differences in Young Adults Hospitalized With Acute Myocardial Infarction [Internet]. Circulation. 2019;139:1047-56.

50. Tu JV, Nardi L, Fang J, Liu J, Khalid L, Johansen H. National trends in rates of death and hospital admissions related to acute myocardial infarction, heart failure and stroke, 1994-2004. CMAJ. CMAJ; 2009;180:E118-25. 


\section{Tables}

Table 1: Baseline characteristics of patients with rheumatoid arthritis according to time of diagnosis, Hordaland, Western Norway.

Time of RA diagnosis

\begin{tabular}{|c|c|c|c|c|}
\hline Characteristics of patients & $\begin{array}{l}1972-1985 \\
(\mathrm{n}=236)\end{array}$ & $\begin{array}{l}1986-1998 \\
(n=535)\end{array}$ & $\begin{array}{c}1999-2013 \\
(n=1050)\end{array}$ & $p$ for trend \\
\hline Women & $171(73 \%)$ & $388(73 \%)$ & $706(67 \%)$ & 0.120 \\
\hline Age at RA diagnosis, years & $52.9(13.0)$ & $54.5(16.3)$ & $56.1(15.9)$ & 0.005 \\
\hline BMI during follow-up, $\mathrm{kg} / \mathrm{m}^{2}$ & $24.3(4.1)$ & $25.2(4.4)$ & $25.6(4.5)$ & $<0.001$ \\
\hline Smoking status at RA diagnosis & & & & $<0.001$ \\
\hline Missing & $27(11 \%)$ & $18(3 \%)$ & $4(0 \%)$ & \\
\hline Non-smoker & $104(50 \%)$ & $268(52 \%)$ & $425(41 \%)$ & \\
\hline Former smoker & $35(17 \%)$ & $86(17 \%)$ & $339(32 \%)$ & \\
\hline Smoker & $70(33 \%)$ & $163(32 \%)$ & $282(27 \%)$ & \\
\hline \multicolumn{5}{|l|}{ Comorbidities $^{a}$} \\
\hline Previous AMI & $11(5 \%)$ & $25(5 \%)$ & $54(5 \%)$ & 0.760 \\
\hline Previous stroke & $2(1 \%)$ & $12(2 \%)$ & $33(3 \%)$ & 0.068 \\
\hline Diabetes & $4(2 \%)$ & $16(3 \%)$ & $68(7 \%)$ & 0.007 \\
\hline Angina & $15(6 \%)$ & $35(7 \%)$ & $57(6 \%)$ & 0.576 \\
\hline Antihypertensive treatment & $24(10 \%)$ & $64(12 \%)$ & $247(24 \%)$ & $<0.001$ \\
\hline Statin treatment & $0(0 \%)$ & $8(2 \%)$ & $131(13 \%)$ & 0.002 \\
\hline ACR/EULAR criteria fulfilled & $200(85 \%)$ & $454(85 \%)$ & $933(89 \%)$ & 0.079 \\
\hline RF/ACPA positive during follow-up & $154(65 \%)$ & $326(61 \%)$ & $719(69 \%)$ & 0.372 \\
\hline $\mathrm{ESR}^{\mathrm{b}}, \mathrm{mm} / \mathrm{h}$ & $56.1(32.3)$ & $49.4(30.9)$ & $43.7(26.0)$ & $<0.001$ \\
\hline $\mathrm{CRP}^{\mathrm{b}}, \mathrm{mg} / \mathrm{l}$ & & & & 0.584 \\
\hline Missing & $227(96 \%)$ & $7(1 \%)$ & $1(0 \%)$ & \\
\hline Mean (SD) & $29.7(49.1)$ & $44.7(44.3)$ & $37.8(44.2)$ & \\
\hline Arthritis on X-ray during follow-up & 207 (88\%) & $370(69 \%)$ & $425(41 \%)$ & $<0.001$ \\
\hline
\end{tabular}


Values in the table are mean $( \pm S D)$ for continuous characteristics and $N(\%)$ for discrete characteristics. ACPA, anti-citrullinated protein antibodies; ACR, American College of Rheumatology; AMI, acute myocardial infarction; BMI, body mass index; CRP, c-reactive protein; ESR, Erythrocyte sedimentation rate; EULAR, European League against Rheumatism; RA, rheumatoid arthritis; RF, rheumatoid factor.

${ }^{\mathrm{a}}$ Before and 1 year after RA diagnosis.

${ }^{\mathrm{b}}$ The highest value within 1 year before and 2 years after the diagnosis of RA.

Table 2: Annual change in rates of acute myocardial infarction and ischemic heart disease for RA patients. 


\begin{tabular}{|c|c|c|c|}
\hline & \multicolumn{3}{|c|}{ Age-adjusted incidence rate ratio (95\% Cl), 1972-2017 } \\
\hline & Total $^{\mathrm{a}}$ & Men & Women \\
\hline & \multicolumn{3}{|l|}{ All ages } \\
\hline AMI & $0.984(0.971-0.998)$ & $0.984(0.961-1.008)$ & $0.984(0.967-1.002)$ \\
\hline \multirow[t]{2}{*}{ IHD } & $0.975(0.964-0.986)$ & $0.974(0.956-0.993)$ & $0.976(0.962-0.990)$ \\
\hline & \multicolumn{3}{|l|}{$16-64$ years } \\
\hline AMI & $0.996(0.967-1.026)$ & $0.987(0.951-1.020)$ & $1.006(0.960-1.056)$ \\
\hline \multirow[t]{2}{*}{$\mathrm{IHD}$} & $0.985(0.963-1.007)$ & $0.970(0.944-0.997)$ & $1.003(0.965-1.042)$ \\
\hline & \multicolumn{3}{|l|}{$65-84$ years } \\
\hline AMI & $0.973(0.957-0.989)$ & $0.976(0.947-1.006)$ & $0.972(0.953-0.991)$ \\
\hline \multirow[t]{2}{*}{ IHD } & $0.971(0.958-0.984)$ & $0.976(0.952-1.000)$ & $0.970(0.954-0.985)$ \\
\hline & \multicolumn{3}{|l|}{$85+$ years } \\
\hline AMI & $1.056(1.003-1.111)$ & $1.118(0.962-1.299)$ & $1.037(0.984-1.093)$ \\
\hline \multirow[t]{4}{*}{$\mathrm{IHD}$} & $1.007(0.959-1.057)$ & $1.064(0.974-1.163)$ & $0.991(0.940-1.046)$ \\
\hline & \multicolumn{3}{|c|}{ Fully adjusted incidence rate ratio $(95 \% \mathrm{Cl}), 1972-2017^{\mathrm{b}}$} \\
\hline & Total $^{\mathrm{a}}$ & Men & Women \\
\hline & \multicolumn{3}{|l|}{ All ages } \\
\hline AMI & $0.984(0.970-0.999)$ & $0.983(0.959-1.008)$ & $0.986(0.968-1.004)$ \\
\hline \multirow[t]{2}{*}{$\mathrm{IHD}$} & $0.968(0.958-0.978)$ & $0.964(0.948-0.980)$ & $0.970(0.957-0.983)$ \\
\hline & \multicolumn{3}{|l|}{$16-64$ years } \\
\hline AMI & $0.997(0.968-1.028)$ & $0.998(0.963-1.033)$ & $1.004(0.953-1.056)$ \\
\hline \multirow[t]{2}{*}{$\mathrm{IHD}$} & $0.977(0.958-0.997)$ & $0.970(0.946-0.995)$ & $0.987(0.953-1.022)$ \\
\hline & \multicolumn{3}{|l|}{$65-84$ years } \\
\hline AMI & $0.971(0.955-0.988)$ & $0.968(0.937-1.000)$ & $0.972(0.953-0.992)$ \\
\hline \multirow[t]{2}{*}{$\mathrm{IHD}$} & $0.964(0.953-0.977)$ & $0.961(0.939-0.983)$ & $0.965(0.951-0.980)$ \\
\hline & \multicolumn{3}{|l|}{$85+$ years } \\
\hline AMI & $1.062(1.008-1.119)$ & $1.144(0.981-1.333)$ & $1.039(0.983-1.098)$ \\
\hline IHD & $0.985(0.945-1.026)$ & $1.011(0.923-1.108)$ & $0.970(0.925-1.017)$ \\
\hline
\end{tabular}


Percent of the average change in rates per year is obtained by subtracting incidence rate ratio from 1 . AMI: acute myocardial infarction; $\mathrm{Cl}$ : confidence interval; IHD: ischemic heart disease.

aSex-adjusted analyses.

${ }^{b}$ Adjusted for age, year, bmi, serological and smoking status

\section{Figures}

3089 patients with 5 or more consultations for

RA and first year of contact 1972 - 2014

\begin{tabular}{|c|c|}
\hline & $\begin{array}{c}13 \text { patients aged below } 16 \\
\text { at first contact }\end{array}$ \\
\hline 3076 patients & \multirow[b]{2}{*}{429 patients without consent } \\
\hline & \\
\hline \multirow{2}{*}{$\begin{array}{l} \\
\quad 2649 \text { patients with consent: } \\
\text { - } 1456 \text { from NorArthritis } \\
\text { - } 214 \text { from letters of consent } \\
\text { - } 979 \text { exemption from consent (dead) }\end{array}$} & \multirow{4}{*}{$\begin{array}{l}828 \text { patients: } \\
\text { - Incorrect RA diagnosis } \\
(\mathrm{n}=279) \\
\text { - Incomplete medical } \\
\text { records }(\mathrm{n}=282) \\
\text { - Treated by private } \\
\text { practicing rheumatologist } \\
(\mathrm{n}=89)\end{array}$} \\
\hline & \\
\hline \multirow[b]{3}{*}{$\downarrow$} & \\
\hline & \\
\hline & \multirow{2}{*}{$\begin{array}{l}\text { RA diagnosis prior to } \\
1972 \text { or after } 2013 \\
(n=178)\end{array}$} \\
\hline $\begin{array}{l}1821 \text { patients included with } \\
\text { RA diagnosed } 1972-2013\end{array}$ & \\
\hline
\end{tabular}

Figure 1

Selection of patients with rheumatoid arthritis, Hordaland, Western Norway. NorArthritis, the Norwegian Arthritis Registry; RA, rheumatoid arthritis. 


\begin{tabular}{|c|c|c|c|c|}
\hline Cohort & Data Source & $1972-2006$ & $2007-2014$ & $2015-2017$ \\
\hline \multirow{2}{*}{ RA cohort } & WENOCARD & & & \\
& Hospital PAS & & & \\
\hline \multirow{2}{*}{ Comparison cohort } & WENOCARD & & & \\
\cline { 2 - 5 } & CVDNOR & & & \\
\hline
\end{tabular}

\section{Figure 2}

Data sources used to identify acute myocardial infarction (AMI) and ischemic heart disease (IHD).

CVDNOR, Cardiovascular Disease in Norway; PAS, patient administrative system; RA, rheumatoid arthritis; WENOCARD, The Western Norway Cardiovascular Registry. 
A

Acute myocardial infarction

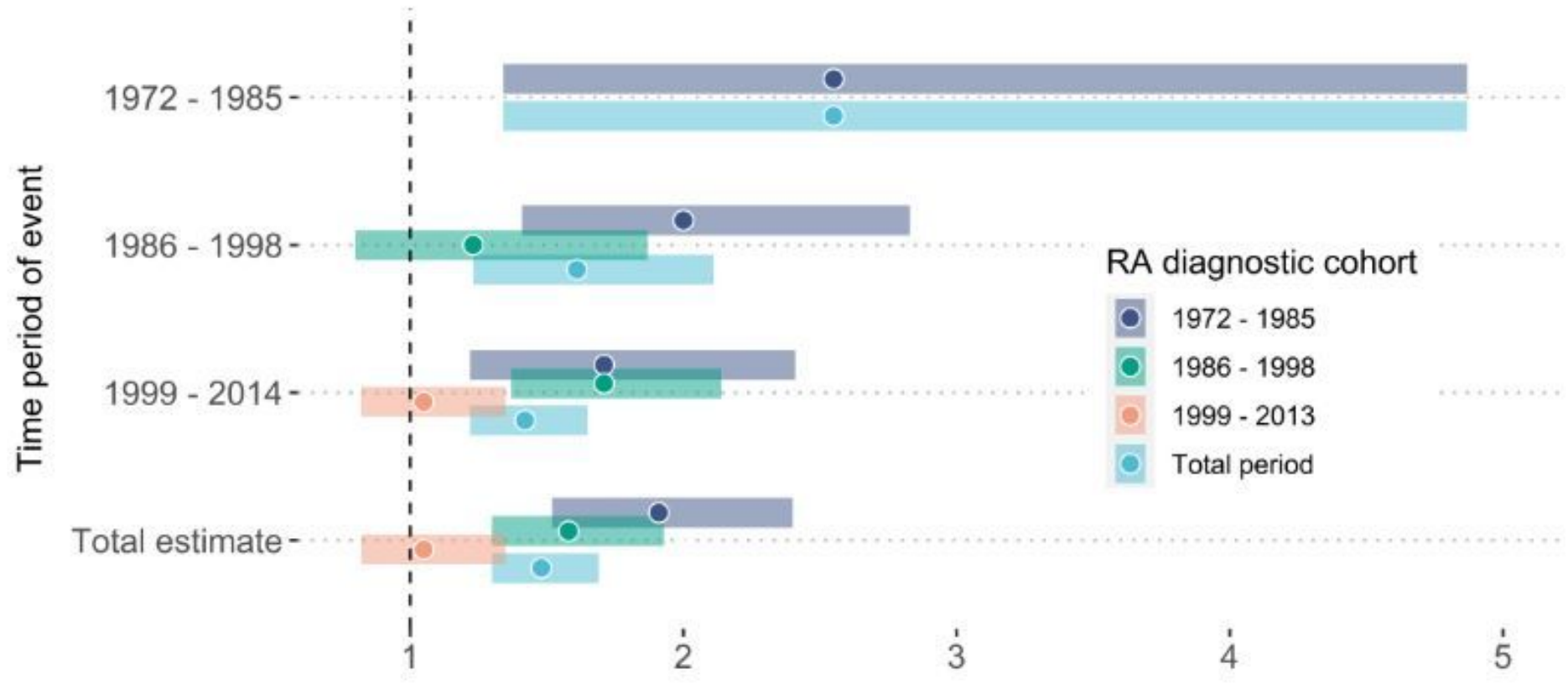

B

Ischemic heart disease

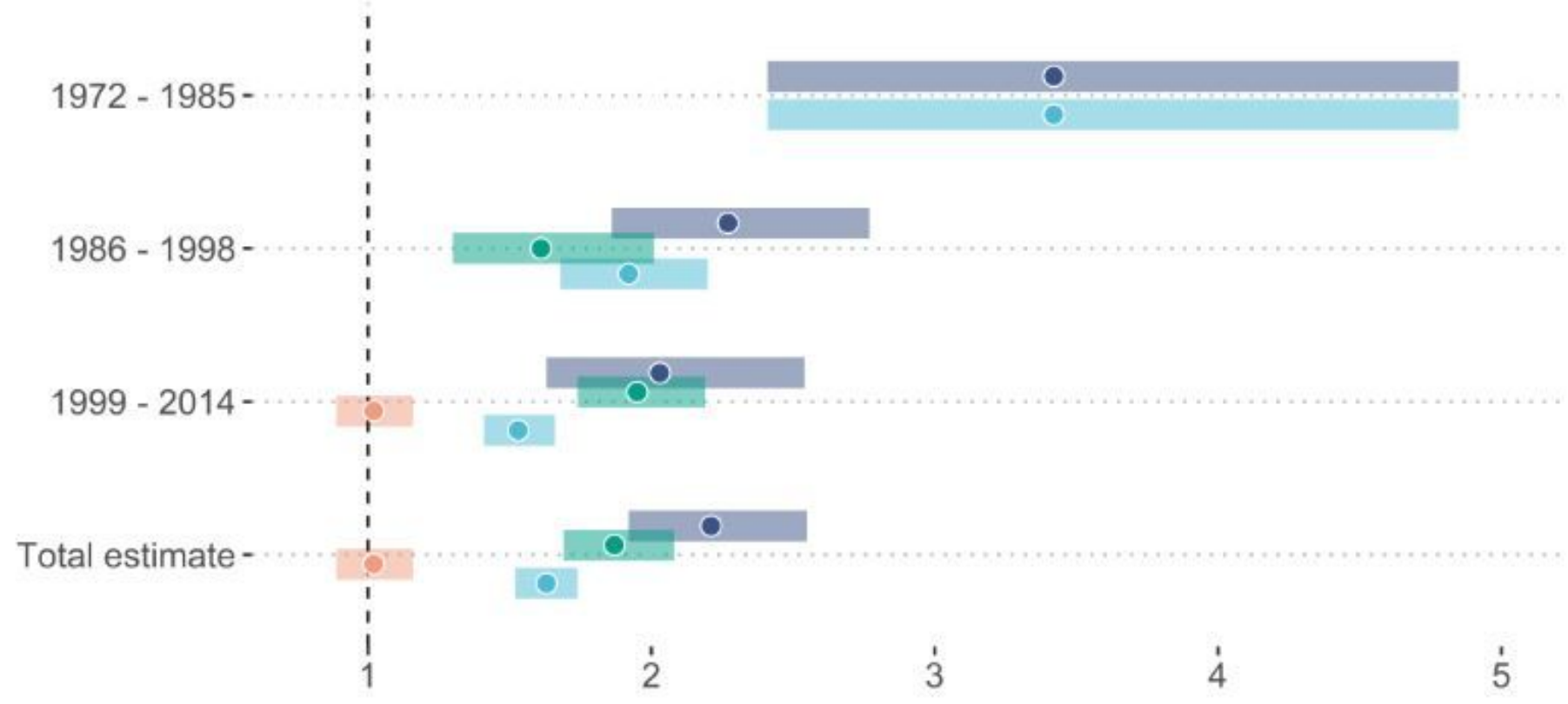

Standardized event ratio

\section{Figure 3}

Excess AMI and IHD risk in rheumatoid arthritis (RA) patients compared with the general population. The estimates are given for three time periods of events (AMI or IHD) and according to the period of RA diagnosis, given with $95 \%$ confidence intervals $(\mathrm{Cl})$. Point estimates are standardized event ratios comparing the number of events in the RA cohort to expected number of events calculated from reference rates in the general population and standardized for age, sex and year of the event. Both the RA and 
general population were obtained from Hordaland, Western Norway. AMI, acute myocardial infarction; $\mathrm{IHD}$, ischemic heart disease.

\section{Supplementary Files}

This is a list of supplementary files associated with this preprint. Click to download.

- Additionalfile.pdf 